\title{
A VOZ CALA, O CORPO GRITA: As Dificuldades de Alunos LGBTs nas Aulas de Educação Física
}

\author{
Aline Rosana Giardin ${ }^{1}$ \\ Jactiane Anzanello ${ }^{2}$ \\ Maria Rosa Chitolina Schettinger ${ }^{3}$
}

\begin{abstract}
RESUMO
O artigo aborda a relação entre as questões de gênero, aceitação do corpo, relações interpessoais e as aulas de educação física no contexto escolar, com o intuito de verificar a realidade desses alunos quanto às aulas de educação física e suas implicações enquanto inclusão (ou exclusão) que poderá resultar em um bom ou mal relacionamento com os colegas. Os dados foram obtidos a partir da aplicação de um questionário com questões abertas e fechadas para alunos de escolas estaduais de diversos municípios do Rio Grande do Sul. Mediante as respostas dos alunos, foi possível verificar que o ambiente escolar e, neste caso, as aulas de educação física, reproduzem e reforçam práticas segregadoras, problemas de relacionamento entre os alunos LGBTs e não LGBTs e a dificuldade de aceitação do próprio corpo. É necessário um olhar mais aprofundado acerca das questões abordadas neste estudo dentro do ambiente escolar e, em especial, nas aulas de educação física, com o intuito de compreender as questões de gênero e evitar a exclusão dos alunos LGBTs.
\end{abstract}

Palavras-chave: Alunos LGBTs. Homofobia. Educação Física. Escolas. Exclusão.

THE VOICE CALLS, THE BODY SCREAMS:

THE DIFFICULTIES OF LGBT STUDENTS IN THE LESSONS OF PHYSICAL EDUCATION.

\section{ABSTRACT}

The article discusses the relationship between gender issues, body acceptance, interpersonal relationships and physical education classes in the school context. In the article I look at the reality of these students within their physical education classes and the implication, of their inclusion (or exclusion) that may result in a good or bad relationship with colleagues. The data was obtained via questionnaire which was completed by students from several state schools in multiple municipalities of Rio Grande do Sul; the questionnaire had both open and closed questions. Through the students' answers, it appeared that the school environment in the case of physical education, reproduces and reinforces segregating practices, which creates relationships difficulties between LGBT and non-LGBT students' and the difficulty of acceptance of the body itself. It is necessary to look more closely at the issues addressed in this study within the school environment and especially in physical education classes, in order to understand gender issues and avoid the exclusion of LGBT students.

Keywords: LGBTs students. Homophobia. Physical Education. Schools. Exclusion.

Recebido em: $15 / 3 / 2018$

Aceito em: 30/6/2019

\footnotetext{
1 Autora correspondente. Universidade Federal de Santa Maria. Av. Roraima, 1000 - Bairro Camobi. CEP 90050-170. Santa Maria/RS, Brasil. http://lattes.cnpq.br/5058576533170357. https//orcid.org/0000-0002-5366-0657. argiardin@gmail.com

2 Universidade Federal do Rio Grande do Sul. Porto Alegre/RS, Brasil. http://lattes.cnpq.br/9017816915805431.

3 Universidade Federal do Rio Grande do Sul. Porto Alegre/RS, Brasil. http://lattes.cnpq.br/4401319386725357. https://orcid.org/00000002-5240-8935.
} 
Nos atuais discursos políticos e pedagógicos há uma emergente notoriedade às questões de gênero e sexualidade. Destaca-se, sobre isso, discussões recentes sobre Planos Nacionais, Estaduais e Municipais de Educação e a retirada do termo "gênero" da redação dos mesmos. Em relação ao currículo do Ensino Fundamental, os Parâmetros Curriculares Nacionais (1998) apontam como temas transversais, entre outros, a questão da orientação sexual ou da diversidade sexual. No Plano Estadual de Educação do Rio Grande do Sul de 2015, aparecem como diretrizes: "a promoção dos princípios do respeito aos direitos humanos, à diversidade e à sustentabilidade socioambiental, à orientação sexual e às escolhas religiosas" e "combate ao racismo e a todas formas de preconceito". É possível que estudantes de Graduação de Licenciatura em educação física não aprendam sobre essa temática, levando a uma falta de preparo na posterior atuação docente.

Desde os anos 60 do século 20, o debate sobre identidade e práticas sociais e de gênero vem se tornando cada vez mais acalorado, especialmente provocado pelo movimento feminista, movimento de gays e lésbicas (LOURO, 1997). Novas identidades sociais tornam-se visíveis, provocando, em seu processo de afirmação e diferenciação, novas divisões sociais e o nascimento do que passou a ser conhecido como "política de identidades" (HALL, 2002). É importante ressaltar que esse movimento evidencia que as identidades de "homem" e "mulher" também fazem parte de construções sociais de identidade, ou seja, gênero faz parte de uma construção social a partir de uma percepção de diferenças biológicas (SCOTT, 1990).

Adolescentes gays e lésbicas, quando comparados com suas homólogas heterossexuais, relatam maiores sentimentos de solidão (MARTIN; D'AUGELLI, 2003), presumivelmente como resultado de seu status marginalizado em suas escolas secundárias.

$O$ reconhecimento da homofobia como um fenômeno discriminatório a ser enfrentado pelas escolas é recente nas políticas públicas de educação no Brasil, tendo o MEC apoiado cursos de capacitação de professores(as) no tema da diversidade sexual (BRASIL, 2008, 2007). A qualificação do material didático-pedagógico, no entanto, permanece um grande desafio. Ela requer iniciativas inovadoras que visem à promoção da igualdade de oportunidades para todas as pessoas, independente das práticas sexuais e/ou performances sociais de gênero, por meio da superação do silêncio sobre a diversidade sexual associado à naturalização da heterossexualidade. A suposição da naturalidade da heterossexualidade como fundamento do laço afetivo e sexual restringe a possibilidade do reconhecimento de famílias constituídas por parceiros do mesmo sexo, bem como inferioriza o envolvimento amoroso entre pessoas do mesmo sexo ao status do não legítimo, do estranho, do outro (BRASIL, 2007, 2008).

Há dois desafios no reconhecimento de que a homofobia deve ser combatida pela educação formal: o primeiro é romper o silêncio dos livros sobre a diversidade sexual; o segundo é encontrar mecanismos discursivos para apresentá-la em uma matriz de promoção da igualdade e da diversidade. A afirmação da diversidade sexual é uma estratégia necessária para o seu reconhecimento como valor social a ser preservado, rompendo com o ciclo de violação de direitos de marginalização das práticas sexuais e performances de gênero não hegemônicas (FRASER, 2008; MACKINNON, 1991). 
As políticas públicas referentes a esses programas são pertinentes no cenário atual, que aponta os elevados índices de violência contra lésbicas, gays, bissexuais, travestis, transexuais e transgêneros - LGBT. Homofobia é "a discriminação contra as pessoas que mostram ou a quem se atribui algumas qualidades (ou defeitos) atribuídos ao outro gênero" (WELZER-LANG, 2001). Também pode ser compreendida como a intolerância ou o medo irracional relativos à homossexualidade, que se expressa por violência física e/ou psíquica. A vivência recorrente dessas violências por pessoas LGBTs pode levar à homofobia internalizada, que é a incorporação de hostilidades quanto à sua própria orientação afetivo-sexual (MOITA, 2003). É um constructo decorrente dos discursos que são produzidos e reproduzidos pelas instâncias socializadoras e que reafirmam a lógica dicotômica sexista e a heteronormatividade compulsória (LOURO, 2001, 1997; FOUCAULT, 1987).

As reflexões de Louro (1997) sobre a percepção de diferenças em relação ao gênero mostram que as distinções entre homens e mulheres têm sido justificadas por meio de explicações teóricas utilizando características físicas, psicológicas, comportamentais, habilidades, talentos e capacidades, "[...] para justificar os lugares sociais, os destinos e as possibilidades próprios de cada gênero" (LOURO, 1997). Ou seja, o que se produz socialmente como uma norma de gênero define lugares possíveis de serem ocupados pelos sujeitos. Além disso, existem critérios rígidos sobre quais gêneros podem ser atribuídos aos sujeitos, de acordo com normas anátomo-fisiológicas, que também delimitam os lugares possíveis de sujeito gendrado.

Quando se fala em inclusão na educação dos corpos, dos gêneros e das sexualidades, afirma-se que os sujeitos são plurais e que essa pluralidade deve ser valorizada e aceita. Para tanto, é necessário reconhecer que existe um sistema de normas de gênero e sexualidade que impõe heterossexualidade compulsória $(\mathrm{RICH}, 1980)$ bem como a cisgeneridade compulsória, enredando-os em representações que os nomeiam como feio ou bonito, apto ou inapto, saudável ou doente, normal ou desviante, masculino ou feminino, heterossexual ou homossexual, cisgênero ou transgênero. Precisamos dar-nos conta de que práticas pedagógicas no campo da educação física, orientadas por esse sistema de regramentos de gênero, reforçam discriminações e exclusões ao invés de ampliar possibilidades de intervenção junto aos sujeitos, possibilitando que, por meio das práticas corporais e esportivas, possam exercer sua cidadania e liberdade constituindo-se como sujeitos sociais (GOELLNER; FIGUEIRA; JAEGER, 2008). Assim, o insucesso escolar, o abandono da escola, os problemas de disciplina, a rigidez dos currículos, etc., levaram a escola, a quem incumbiria integrar e acolher a todos, a ser, ela própria, um instrumento de seleção que, em muitos casos, acentuava as diferenças culturais e de características e capacidades pessoais dos alunos (RODRIGUES, 2001).

\section{OS/AS PROFESSORES/AS E QUESTÕES REFERENTES À DIVERSIDADE SEXUAL E DE GÊNERO}

Os discursos que promovem ou praticam a humilhação e a exclusão e violência contra a população LGBT, opõe-se aos direitos de cidadania, pois impedem que alguns desfrutem desses direitos. Essa constatação denuncia a concepção de cidadania como 
privilégio de alguns em detrimento de outros, e a existência do preconceito na comunidade democrática. Essa forma de exclusão permanece, muitas vezes, inviabilizada nas hierarquizações do preconceito social (PRADO; MACHADO, 2008).

Os significados elaborados pelos/as participantes da comunidade escolar não se limitam às ações humanas intencionais: os processos se dão mediante o entrelaçamento de ações intencionais, nem sempre movidas pela razão, em figurações sociais que vão além da comunidade escolar. Essas figurações também se formulam em outros contextos nos quais os participantes das escolas movimentam-se. Os indivíduos movem-se por paixões e emoções alicerçadas em contextos familiares e religiosos, entre tantos outros que fazem da sexualidade um campo de controvérsias (TORRES, 2013).

\section{AS AULAS DE EDUCAÇÃO FÍSICA: Ambiente Libertador ou Segregador?}

Considerando a importância da intervenção pedagógica de profissionais que atuam no campo das práticas corporais e esportivas, devemos buscar fornecer alguns subsídios teóricos acerca de questões relacionadas aos corpos, aos gêneros e às sexualidades, com o intuito de alertar para a necessidade de reconhecermos a diversidade e, assim, promovermos situações nas quais esta seja respeitada (GOELLNER; FIGUEIRA; JAEGER, 2008).

O/a professor/a de Educação Física contribui, muitas vezes, na disseminação do preconceito e da discriminação, reforçando estereótipos por meio de seu discurso, ou até mesmo impedindo pessoas percebidas como "desviantes das normas de gênero" de frequentar suas aulas. Existem também professores/as que, embora não tenham explicitamente tais comportamentos, não tomam nenhuma atitude efetiva no sentido de impedir as discriminações por parte dos outros alunos/as.

As chacotas, bullying, piadas e brincadeiras que visam a subjugar o "outro", visibilizam o quanto algumas situações ocorrentes nas aulas constroem a representação abjeta do sujeito homossexual ou que não performatiza uma masculinidade próxima da considerada aceitável. É nesse sentido que Priscila Gomes Dornelles (2013) afirma que a Educação Física é uma disciplina escolar que deve ser problematizada no sentido de questionar que corpo se pretende formar e como a escola constrói mecanismos reguladores para que tal objetivo seja alcançado.

Diante dessas premissas e do difícil cotidiano dessa população em nossas escolas, decidimos investigar em escolas gaúchas, de diferentes cidades, a realidade desses alunos quanto às aulas de educação física e suas implicações enquanto inclusão (ou exclusão) desses, o que poderá resultar em um bom ou mal relacionamento com os colegas.

\section{PROCEDIMENTOS METODOLÓGICOS}

Esta pesquisa consistiu-se em um estudo transversal, de caráter descritivo e abordagem quantitativa. Participaram dela alunos de Escolas Estaduais do Rio Grande do Sul, e os dados foram coletados no período entre maio e dezembro de 2016.

$O$ estudo investigou as dificuldades de estudantes LGBTs relativas às questões de gênero, aceitação do corpo, relações interpessoais e as aulas de educação física no contexto escolar, e foi realizado em escolas de diferentes cidades do Rio Grande do Sul. 
Para tanto, foram selecionadas regiões diferentes de nosso Estado: além da capital Porto Alegre, as cidades de Alegrete, Cacequi, Torres, Pelotas, Canoas e Santa Rosa foram escolhidas.

O grupo estudado foi composto por 503 estudantes com idades entre 13 e 21 anos, que foram divididos em grupos: LGBTs (Lésbicas, gays, bissexuais, transexuais/travestis/transgênero) e não LGBTs (ou seja, heterossexuais e cisgênero ao mesmo tempo).

Para a coleta de dados, inicialmente foi encaminhado o Termo de Consentimento Livre e Esclarecido (TCLE) para os pais dos alunos menores de idade, com o intuito de informar os objetivos da pesquisa e solicitar a autorização para estes participarem do estudo. A coleta de dados foi realizada por meio da aplicação de um questionário que foi elaborado especificamente para este trabalho.

O questionário continha perguntas abertas e fechadas e abordou questões sobre gênero, aulas de educação física, corpo e a relação com os colegas. Cada pergunta referia-se à análise de uma questão específica, contendo um total de dez questões. Foram considerados os questionários respondidos de forma completa e foi possível contar com os professores e professoras das escolas participantes. Estes profissionais selecionaram algumas turmas e aplicaram o questionário no fim da aula. Após aplicação, os questionários foram colocados dentro de um envelope e devolvidos ao(a) professor(a). A coleta dos dados foi realizada mantendo a privacidade e o anonimato dos alunos participantes.

O estudo teve a aprovação do Comitê de Ética em Pesquisa da Universidade Federal de Santa Maria (UFSM) sob parecer no 2271159. O Termo de Consentimento Livre e Esclarecido foi formulado tomada por base a Resolução 196/96 do Conselho Nacional de Saúde.

\section{ANÁLISE E DISCUSSÃO DOS RESULTADOS}

Foram encaminhados 800 questionários aos alunos das Escolas estaduais do Rio Grande do Sul. Não retornaram 297 questionários, o que é considerado um número significativo, pois pode-se inferir a não aceitação dos pais em expor questões de gênero dos seus filhos, o que fortalece questões de repressão quanto à sexualidade e ao gênero.

O grupo estudado foi composto por 503 estudantes, entre 13 e 21 anos, que foram divididos em: LGBTs (Lésbicas, gays, bissexuais, transexuais/travestis/transgênero) e não LGBTs (ou seja, heterossexuais e cisgênero ao mesmo tempo), de acordo como se identificavam nos questionários.

Ao responder ao questionário, caso a resposta da pergunta "Você se considera" fosse bissexual, gay, lésbica, transgênero ou transexual, os alunos eram considerados do grupo LGBTs. Se a resposta fosse "Heterossexual", ou "nenhum", então os alunos eram considerados não LGBTs. Não foi explicitado o conceito de "cisgênero" no questionário, pois este é um conceito ainda desconhecido por grande parte da população. Cisgênero é a pessoa que se reconhece como pertencendo ao gênero que foi compulsoriamente designada quando nasceu. Ou seja, nasceu com um pênis e, por conta disso, foi compulsoriamente designado como homem e se reconhece como homem; nasceu com vagina e foi compulsoriamente designada como mulher, e se reconhece como mulher. 
As características do grupo estudado, relativas à idade, sexo e identificação (LGBTs ou não LGBTs), estão descritos na Tabela 1.

Tabela 1 - Caracterização da amostra

\begin{tabular}{l|c}
\hline Características & Amostra total $(n)$ \\
\hline & $n=503$ \\
Idade (anos) - Média & $\pm 17(12-21)$ \\
Sexo $-\mathrm{n}$ & \\
Masculino & 234 \\
Feminino & 269 \\
LGBT & 107 \\
Não LGBT & 396 \\
\hline
\end{tabular}

Fonte: Os autores.

É possível observar que, dos 503 alunos que responderam ao questionário, 107 alunos identificam-se como LGBTs. Destes, a maior parte $(n=44)$ consideram-se bissexuais. A caracterização geral dos alunos LGBTs encontra-se no Gráfico 1.

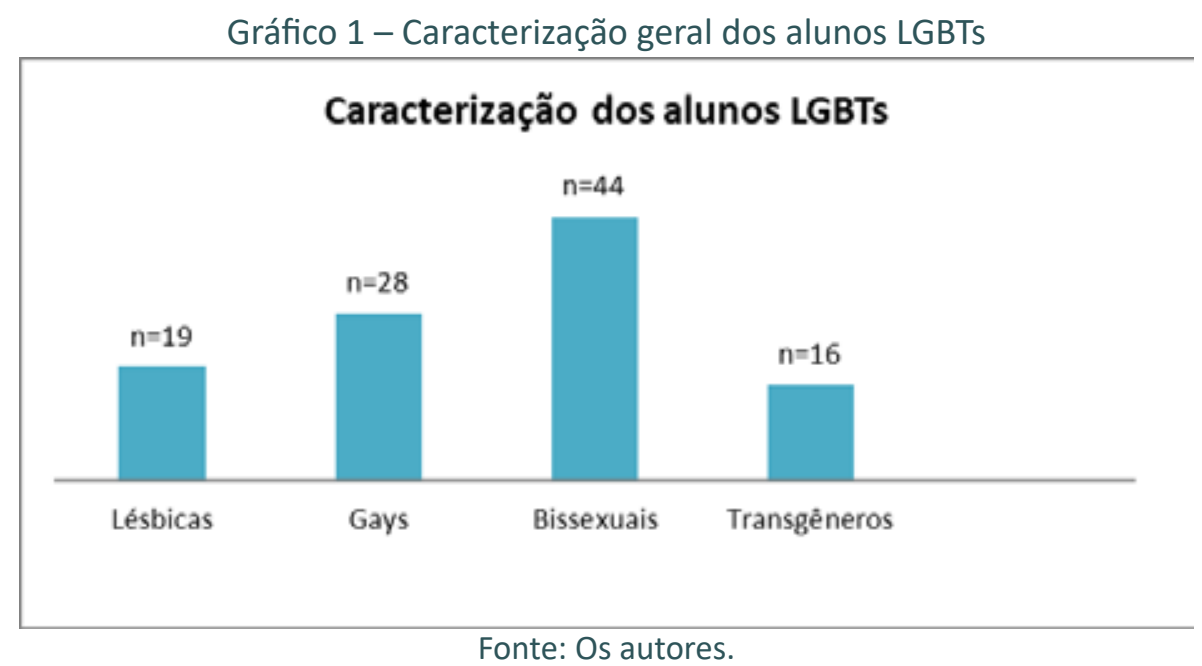

As alunas LGBTs do sexo feminino totalizaram $n=58$ e possuíam idade média de 15 anos. Dentre estas, 32 alunas consideram-se bissexuais. A caracterização das alunas LGBTs do sexo feminino encontram-se na Tabela 2.

Tabela 2 - Caracterização dos alunos LGBTs por sexo - feminino

\begin{tabular}{l|c}
\hline Características & Amostra LGBTs $(n)$ \\
\hline Idade & \pm 15 \\
Sexo Feminino & 58 \\
Lésbicas & 19 \\
Bissexuais & 32 \\
Transgêneros & 7 \\
\hline
\end{tabular}

Fonte: Os autores. 
Os alunos LGBTs do sexo masculino totalizaram $n=49$ e com média de idade de $\mathrm{n}=16$ anos. A maior parte destes alunos $(\mathrm{n}=28)$ descreveram-se como gays. A caracterização dos alunos LGBTs do sexo masculino encontram-se na Tabela 3.

Tabela 3 - Caracterização dos alunos LGBTs por sexo - masculino

\begin{tabular}{l|c}
\hline Características & Amostra LGBTs(n) \\
\hline Idade & $\pm 16,5$ \\
Sexo Masculino & 49 \\
Gays & 28 \\
Bissexuais & 12 \\
Transgêneros & 9 \\
\hline
\end{tabular}

Fonte: Os autores.

A partir destes dados foram avaliadas as dificuldades dos/as estudantes nas aulas de educação física.

Quanto às questões que constituíram os questionários, as duas perguntas iniciais referiam-se à participação dos alunos nas aulas de educação física e sua percepção de as aulas contemplarem a todos/as os/as alunos/as. As respostas à questão que diziam respeito à participação nas aulas de Educação Física encontram-se na Tabela 4.

Tabela 4 - Respostas às questões sobre a participação nas aulas de Educação Física

\begin{tabular}{|l|l|l|l|l|l|l|}
\hline \multicolumn{7}{|c|}{ “Você participa das aulas de educaço física?” } \\
\hline & Não LGBTs & LGBTs & Gays & Lésbicas & Bissexuais & Transgêneros \\
\hline $\mathbf{n}$ & 396 & 107 & 28 & 19 & 44 & 16 \\
\hline Sim & 361 & 69 & 15 & 14 & 31 & 9 \\
\hline Não & & 4 & 1 & & 2 & 1 \\
\hline $\begin{array}{l}\text { Às vezes, quando a aula } \\
\text { interessa }\end{array}$ & 14 & 19 & 3 & 4 & 8 & 4 \\
\hline $\begin{array}{l}\text { Raramente, as aulas } \\
\text { não me interessam }\end{array}$ & 19 & 6 & - & 1 & 3 & 2 \\
\hline $\begin{array}{l}\text { Se pudesse não } \\
\text { participaria }\end{array}$ & 2 & 9 & 9 & - & - & - \\
\hline
\end{tabular}

Fonte: Os autores.

Existe uma questão específica sobre a disciplina de educação física que se refere a esse quesito, pois, por se tratar de uma disciplina da ordem prática de atividade física, frequentemente os/as estudantes preferem não participar das atividades, mesmo que seja disciplina obrigatória. É uma situação diferente de disciplinas que utilizam somente a cognição mental, quando não se pode perceber explicitamente a participação ou não de estudantes.

Dentre os/as entrevistados/as, 107 alunos LGBTs afirmaram participar das aulas, porém 38 declararam que pouco participavam ou, se pudessem, não participariam. A princípio, essa pergunta não investiga a razão dessa escolha, mas as respostas posteriores indicam situações que podem corroborar esse dado. O Brasil concentra $82 \%$ da evasão escolar de travestis e transgêneros. A informação é do defensor público João 
Paulo Carvalho Dias, que é presidente da Comissão de Diversidade Sexual da Ordem dos Advogados do Brasil e membro conselheiro do Conselho Municipal de Políticas LGBT (Lésbicas, Gays, Bissexuais, Travestis, Transexuais e Transgêneros) em Cuiabá-MT.

Na questão relativa à percepção dos alunos sobre as aulas de educação física contemplarem a todos/as, 21 alunos LGBTs responderam que as aulas não contemplavam todos os alunos participantes. As respostas à questão referente à participação nas aulas de educação física encontram-se na Tabela 5.

Tabela 5 - Respostas à questão sobre as aulas contemplarem todos os alunos

\begin{tabular}{|l|c|c|c|c|c|c|}
\hline \multicolumn{2}{|c|}{ “Você acha que as aulas de educação física de sua escola são boas para todos os alunos?” } \\
\hline & Não LGBTs & LGBTS & Gays & Lésbicas & Bissexuais & Transgêneros \\
\hline $\mathrm{n}$ & 396 & 107 & 28 & 19 & 44 & 16 \\
\hline Sim & 381 & 86 & 20 & 17 & 39 & 10 \\
\hline Não & 15 & 21 & 8 & 2 & 5 & 6 \\
\hline
\end{tabular}

Fonte: Os autores.

A justificativa negativa, dada pela maioria desses alunos, referiu-se às aulas repetidas, segregadas, e que não levavam em conta a vontade e a real necessidade deles.

Outra questão referia-se sobre os alunos sentirem-se desconfortáveis durante as aulas de educação física. A maior parte $(n=77)$ relatou não sentir desconforto, e 30 alunos afirmaram sentir desconforto físico por não saberem executar algumas atividades ou porque não se sentiam atraídos pelas aulas propostas. $O$ objetivo desta pergunta foi investigar possíveis desconfortos ou constrangimentos em algum tipo de atividade. As respostas à questão sobre os alunos sentirem desconforto nas aulas de Educação Física encontram-se na Tabela 6.

Tabela 6 - Respostas à questão sobre sentirem desconforto durante as aulas de EF

\begin{tabular}{|l|l|l|l|l|l|l|}
\hline \multicolumn{7}{|c|}{ “Você se sente mal, ou desconfortável, nas aulas de educação física?” } \\
\hline & Não LGBTs & LGBTs & Gays & Lésbicas & Bissexuais & Transgêneros \\
\hline n & 396 & 107 & 28 & 19 & 44 & 16 \\
\hline Não me sinto mal & 389 & 77 & 18 & 15 & 35 & 9 \\
\hline Sim, me sinto mal & 7 & 30 & 10 & 4 & 9 & 7 \\
\hline
\end{tabular}

Fonte: Os autores.

Pressupõe-se na escola, "conceitualmente, que todos, sem exceção, devem participar da vida acadêmica, em escolas ditas comuns e nas classes ditas regulares onde deve ser desenvolvido o trabalho pedagógico que sirva a todos, indiscriminadamente" (CARVALHO, 1998).

Outra questão referia-se ao desejo de mudanças nas aulas de educação física: "Se você pudesse mudar as aulas de Educação física, como elas seriam? Quais atividades você iria sugerir?"

A maior parte das respostas dos alunos LGBTs mostrava o desejo de ter atividades mistas (meninos e meninas) e variadas, e confirmava a repetição de um modelo de aula que tem um forte elemento de gênero: "vôlei para meninas e futebol para meninos". Isso demonstra como a educação física está intensamente permeada pela pedagogia do 
gênero (GOELLNER, 2008; LOURO, 1997), em que não se ensina um conteúdo "neutro" em relação ao gênero, e sim, é por essa disciplina que se aprende normas sociais relativas a como deve portar-se um homem e como deve-se portar uma mulher.

Assim, é por meio de um conteúdo repetido e reiterado de possibilidades de atividades que se reforçam os comportamentos gendrados. A educação física expõe os estereótipos de gênero por ser uma disciplina que promove a relação de contato e de movimento dos corpos. Ela não está isolada, pois quem a reforça é a escola, conforme aponta Rosemberg (1995).

A questão relacionada ao desejo dos alunos de realizar alguma atividade durante as aulas de educação física e esta não ser considerada "possível" pelo aluno, abordou a dúvida sobre a não aceitação da prática de atividades ou esportes que são considerados masculinos ou femininos. Podemos citar as respostas de algumas meninas que afirmaram ter vontade de jogar futebol, porém temem ser percebidas como menos femininas por conta disso, e serem taxadas de homossexuais. Algumas dessas meninas também relataram a não inserção em times de futebol por ordem dos pais. Segundo Anne Flintoff (1994), a discriminação na educação física e no esporte é construída em cima de uma imagem estereotipada que reforça a identidade masculina dessas práticas culturais. Logo, tudo o que se relaciona à feminilidade é considerado negativo nesses ambientes.

No contexto do futebol feminino existe o discurso da masculinização da mulher associado ao estereótipo do corpo feminino imposto pela sociedade; "[...] o corpo expressa uma cultura e esta determina corpos" (DAOLIO, 2003), ou seja, uma vez que o esporte é posto como um campo de construção de masculinidade, existe essa preocupação de que a prática do futebol poderia masculinizar as mulheres. Ao mesmo tempo, a adesão, em certa medida, a esses valores, que são considerados masculinos, também permite a essas mulheres praticar o esporte.

O esporte competitivo é uma instituição social que se organiza principalmente em torno do projeto político de definir certas formas de masculinidade como aceitáveis ao denigrar outras formas de masculinidade (ANDERSON, 2010; MESSNER, 2002). Esportes associam meninos e homens com dominância masculina construindo suas identidades e esculpindo seus corpos para alinharem com as perspectivas hegemônicas da encarnação e expressão masculinistas. Meninos em esportes competitivos em equipe são, portanto, construídos para exibir, valorizar e reproduzir noções tradicionais de masculinidade (BRACKENRIDGE et al., 2008).

Destacam-se, aqui, ocorrências de situações em que esportes são marcados por um pertencimento a um gênero, e, portanto, estudantes sente-se proibidos/as de praticá-los. Pode-se exemplificar com a vontade de fazer ginástica artística por meninos, entretanto a crença em relação ao gênero os faz pensar que seus corpos não foram feitos para as artes, por ser "de homem". Nessa questão ficou explícito que alunos LGBTs têm mais dificuldades em algumas tarefas do que não LGBTs. Não estamos falando em dificuldades motoras ou aptidões físicas, mas da dificuldade de demonstrar seus interesses, seus desejos, as potências e os limites de seu corpo.

Acredita-se que as aulas de educação física são o momento em que o corpo está em evidência, quando adquire um significado social. Diferente das salas de aula, onde os alunos permanecem em seus lugares, nas aulas de educação física o aluno está des- 
nudo de mesa, cadeiras, paredes e cadernos. Estão com as mãos livres, agentes sobre seu próprio corpo, e não é necessário permanecer sentados/as. Essa, talvez, seja uma imagem utópica, mas que seria simples executar se, ao contrário de aulas que focassem em limitar as expressões possíveis de serem exploradas, pudéssemos incitar este corpo a experimentar as mais diversas possibilidades.

As últimas questões referiam-se à concepção e aceitação do próprio corpo pelos alunos/as. Na pergunta "Você gosta do seu corpo?", 40 alunos LGBTs responderam "sim", 25 "não", e 42 afirmaram que gostariam que seu corpo fosse diferente. Considerando a faixa etária, podem existir questões particulares à adolescência permeando essas respostas, mas ainda assim é um dado relevante para essa disciplina, que evidencia a construção cultural dos corpos. O corpo parece ter ficado fora da escola. Essa é, usualmente, a primeira impressão quando observamos as mais consagradas teorias educacionais ou os cursos de preparação docente. Talvez não nos surpreendamos com isso, uma vez que nossa formação no contexto filosófico do dualismo ocidental leva-nos a operar, em princípio, com a noção de uma separação entre corpo e mente (HOOKS, 1999).

Sobre a questão "Qual parte do corpo você mais gosta", obtivemos uma gama de respostas, desde pernas até os olhos; entretanto na pergunta "Qual parte do corpo você menos gosta?" obtivemos respostas focadas em partes corporais associadas à feminilidade e masculinidade, como órgãos genitais, mamas, barba. Esse é um dado importante para refletir sobre o papel da educação física na construção de um ideal de corpo masculino ou feminino e verificar como essa construção afeta meninos e meninas cujos corpos não correspondem a esse ideal.

Um exemplo relacionado à sigla LGBTs são as pessoas trans (transexuais, travestis, transgênero) que, frequentemente, têm sua identidade de gênero deslegitimada a partir de critérios anátomo-fisiológicos. Nessa interação com a produção de ideais, muitos/ as jovens podem vir a repudiar partes do corpo que representam essas associações com o gênero errado.

Essas ideias surgem nas respostas da pergunta "Se você pudesse mudar alguma coisa em seu corpo, como ele seria?" Para esta pergunta apareceram respostas relacionadas à genitália e caracteres sexuais secundários. A vontade de mudar essas partes do corpo está relacionada com o aprendizado de que eles representam as supostas masculinidades ou feminilidades, e que seriam necessários para a vivência enquanto homem ou enquanto mulher.

É importante que estes/as alunos/as possam ter modelos de corpos diversos em relação a vivenciar masculinidade e feminilidade, para que possam entender que não existe uma essência de gênero vinda da fisiologia. Assim, poder-se-ia reduzir a associação negativa a estas partes do corpo por pessoas trans. Podemos notar, também, que meninos gays têm problemas com o peso, pois muitos referiam querer ser mais magros ou reclamaram pelo fato de serem um pouco "gordinhos". Já as meninas parecem aceitar melhor o corpo, mesmo algumas desejando um corpo 'mais robusto, mais possante". 
Comparando os questionários com os de alunos não LGBTs, percebemos que alunos LGBTs têm muito mais dificuldades com a concepção e aceitação do corpo. Nos questionários de alunos não LGBTs, estes referem aceitar o corpo como ele é na maioria das respostas, o que nos mostra que, quando o corpo "como ele é" está mais próximo da norma regradora de gênero, ele é mais fácil de ser aceito.

A última questão refere-se ao relacionamento interpessoal na escola: "Como é a relação com seus colegas? Tens algum colega LGBTs? Como é a relação com ele(a)?". Nesta pergunta ficou clara a melhor aceitação que meninas lésbicas têm em relação aos meninos gays. Meninos gays, em sua maioria, afirmaram não ter uma boa relação com os colegas não gays, e alguns até caracterizaram a relação como "péssima". Observando as respostas dos alunos não LGBTs, alguns meninos responderam que meninos gays são "afetados", "se ofendem com brincadeiras" ou "são muito cheio de frescuras".

Pesquisas de Wendel, Toma e Morphew (2001), Hekma (1998) e Price (2000) evidenciam que o potencial transformador dos atletas homossexuais no esporte é neutralizado por meio de homofobia potencialmente evidente e também por intermédio de mecanismos secretos, como a ampliação da linguagem discriminatória (chacotas) e da linguagem contra o discurso, identidade e comportamento gay.

Pesquisas adicionais descobriram que os adolescentes na Espanha não são receptivos à ideia de estender direitos civis básicos a indivíduos que são homossexuais (SOTELO, 2000). A esperança de que as atitudes em relação aos indivíduos que são gays ou lésbicas melhorem com o tempo é um otimismo irrealista, pois esses estudos mostram que a homofobia é profundamente instilada na nova geração de jovens.

Ao contrário de meninos gays, meninas lésbicas ou bissexuais são mais bem aceitas e, muitas vezes, respeitadas pela turma. Os motivos, porém, não são animadores, pois nas respostas de colegas LGBTS e não LGBTs apareceram frases como: "elas parecem uns homens", "são mais fortes", "tem liderança", "tenho um pouco de medo delas". Fica explícita a valoração da masculinidade, pois as meninas conseguem respeito quando assumem uma postura masculina diante de seus colegas.

A construção cultural do corpo feminino foi feita seguindo-se de um paradigma heterossexual baseado na hegemonia masculina e submissão feminina a partir da percepção de diferenças biológicas (RUBIO, 1999), o que fez e faz com que as mulheres tenham de romper barreiras de gênero, assentadas em pressupostos biológicos que as situam como inferiores aos homens na prática atlética, "[...] contribuindo para que elas necessitem transformar o próprio corpo, instrumento de emancipação, para incluírem no universo da competição esportiva, construída com base nos valores em que elas estão em desvantagem, e que nunca teve como finalidade torná-las mais femininas", ao contrário dos homens, para os quais o esporte foi e tem sido um meio de construção da masculinidade (DEVIDE, 2005).

Dada a evidência documentando a existência de homofobia no nosso sistema escolar (D’AUGELLI, 1989, 1992; FRANKLIN 2000), é razoável esperar que a experiência do ensino médio tenha consequências negativas para muitos estudantes que se identificam como gays ou lésbicas. Russell, Seif e Truong (2001) realizaram um estudo com uma amostra nacionalmente representativa de jovens gays, lésbicas e bissexuais e encontraram resultados consistentes com essa suposição. Os homens que são bissexuais sofrem 
academicamente e são mais propensos do que os estudantes que são homossexuais, lésbicas ou heterossexuais a ter problemas na escola (ou seja, não fazer dever de casa, não prestar atenção em sala de aula e enfrentar problemas interpessoais)

Para Butler (2003), "Um arsenal que regula não apenas a sexualidade, mas também o gênero. As disposições heteronormativas voltam-se a naturalizar, impor, sancionar e legitimar uma única equência sexo-gênero-sexualidade: a centrada na heterossexualidade e rigorosamente regulada pelas normas de gênero, as quais, fundamentadas na ideologia do 'dimorfismo sexual', agem como estruturadoras de relações sociais e produtoras de subjetividades".

Não por acaso, heterossexismo e homofobia agem entre outras coisas, instaurando um regime de controle e vigilância não só da conduta sexual, mas também das expressões e das identidades de gênero, como também das identidades raciais. Por isso, podemos afirmar que o heterossexismo e a homofobia são manifestações de sexismo, não raro associadas a diversos regimes e arsenais normativos, normalizadores e estruturantes de corpos, sujeitos, identidades, hierarquias e instituições, tais como o classismo, o racismo e a xenofobia (JUNQUEIRA, 2009).

\section{CONSIDERAÇÕES FINAIS}

O presente trabalho apontou questões que vão além do estilo das aulas, consideradas por vezes repetitivas e segregadoras de educação física. Os discursos construídos tratam, muitas vezes, de "arranjar" a estrutura escolar de uma forma em que é mais fácil deixar "invisibilizar" as diversidades e diferenças que nela coexistem. O fato de a questão LGBT não ser abordada nas aulas de Educação física no que diz respeito às discussões em torno das concepções das atividades propostas, acaba por produzir a segregação de corpos que não se enquadram em uma norma heterossexual e em uma perfomance esperada para aquele corpo.

As respostas dos questionários reiteram essas afirmações, uma vez que meninos sofrem mais com o preconceito do que meninas, resultado de uma construção de masculinidade relacionada sempre à afirmação da heterossexualidade e poder. Neste sentido, a homofobia acaba por desempenhar uma forte influência no controle dos corpos e das sexualidades no ambiente esportivo, pois contribui para o estabelecimento de espaços e práticas sociais diferenciados para aqueles e aquelas que se adéquam à norma heterossexual hegemônica e a todos os demais que se desviam dela.

A partir das respostas que surgiram, consideramos que as aulas de educação física não são neutras, pois os sujeitos não são livres de preconceitos. Neste sentido, o papel da escola, enquanto formadora de opinião, deveria ser o de promover um respeito às diferenças, à diversidade, assim como os professores de educação física devem estar mais envolvidos em ações de enfrentamento ao preconceito por meio de aulas mais inclusivas. 


\section{REFERÊNCIAS}

ANDERSON, Eric. Sport theory and social problems: A critical introduction. New York: Routledge, 2010. BRACKENRIDGE, Celia; ALLRED, Pamela; JARVIS, Alan; MADDOCKS, Kattie; RIVERS, lan. A literature review of sexual orientation in sport. London: Sport Scotland; Sport Northern Ireland; Sport Scotland; UK Sport, 2008.

BRASIL. Ministério da Educação. Secretaria de Educação Continuada, Alfabetização e Diversidade (Secad). Gênero e diversidade sexual na escola: reconhecer e superar preconceitos Cadernos Secad, Brasília, DF, 4, 2007.

BRASIL. Secretaria Especial de Direitos Humanos (SEDH). Texto-base da Conferência Nacional de Gays, Lésbicas, Bissexuais, Travestis e Transexuais. Brasília: SEDH. Disponível em: http://www.presidencia.gov. br/estrutura_presidencia/sedh/brasilsem/IConf/. Acesso em: 13 ago. 2008.

BUTLER, Judith. Cuerpos que importan. Buenos Aires: Paidós, 2002.

BUTLER, Judith. Problemas de gênero. Rio de Janeiro: Civilização Brasileira, 2003.

BUTLER, Judith. Corpos que pesam: sobre os limites discursivos do "sexo". In: LOURO, Guacira L. (org.). $O$ corpo educado. Belo Horizonte: Autêntica, 1999.

CARVALHO, Rosita Edler. Temas em educação especial. Rio de Janeiro: WVA, 1998.

CASTRO, M. G. C.; ABRAMOVAY, M.; SILVA, L. B. Juventudes e sexualidade. Brasília: Unesco Brasil, 2004.

CONSELHO NACIONAL DE COMBATE À DISCRIMINAÇÃO. Brasil sem homofobia: Programa de combate à violência e à discriminação contra GLTB e promoção da cidadania homossexual. Brasília: Ministério da Saúde, 2004.

CORREIA, W. R. Planejamento participativo e o ensino de Educação Física no 2o grau. Revista Paulista de Educação Física, supl. n. 2, p. 43-48, 1996.

COSTA, C. M. Educação Física diversificada, uma proposta de participação. SEMINÁRIO DE EDUCAÇÃO FíSICA ESCOLAR, 4., 1997. São Paulo. Anais [...].São Paulo: USP; Escola de Educação Física e Esporte, 1997. p. 47.

D’AUGELLI, Anthony R. Lesbians' and Gay Men's Experiences of Discrimination and Harassment in a University Community. American Journal of Community Psychology, 17, p. 317-321, 1989.

D’AUGELLI, Anthony R. Lesbian and Gay Male Undergraduates' Experience of Harassment and Fear on Campus. Journal of Interpersonal Violence, 7, 1992.

DAOLIO, Jocimar. Cultura, educação física e futebol. 2. ed. Campinas: Unicamp, 2003.

DE ÁVILA, A. C. V. Para além do esporte: a expressão corporal nas aulas de Educação Física do segundo grau. 1995. Monografia (Graduação) - Unesp, Instituto de Biociências, Departamento de Educação Física, Rio Claro, 1995.

DEVIDE, F. P. Gênero e mulheres no esporte: história das mulheres nos Jogos Olímpicos Modernos. Ijuí: Editora Unijuí, 2005.

DORNELLES, Priscila Gomes. A (hetero)normalização dos corpos em práticas pedagógicas da Educação Física escolar. 2013. 193 f. Tese (Doutorado em Educação) - Universidade Federal do Rio Grande do Sul, Porto Alegre, 2013.

FLINTOFF, Anne. Sexism and homophobia in physical education: the challenge for teacher educators. Physical Education Review, v. 17, n. 2, 1994.

FOUCAULT, M. Vigiar e punir. 7. ed. Petrópolis: Vozes, 1987.

FRANKLIN, Karen. Antigay Behaviors among Young Adults: Prevalence, Patterns, and Motivators in a Noncriminal Population. Journal of Interpersonal Violence, 15, 2000.

FRASER, N. Redistribuição, reconhecimento e participação: por uma concepção integrada da justiça. In: SARMENTO, D.; IKAWA, D.; PIOVESAN, F. (org.). Igualdade, diferença e direitos humanos. Rio de Janeiro: Lúmen Júris, 2008. p. 167-190.

GOELLNER, Silvana V. A produção cultural do corpo. In: LOURO, Guacira; FELIPE, Jane; GOELLNER, Silvana. Corpo, gênero e sexualidade: um debate contemporâneo na educação. 3. ed. Petrópolis: Vozes, 2008.

GOELLNER, Silvana Vilodre; FIGUEIRA, Márcia Luiza Machado; JAEGER, Angelita Alice. A educação dos corpos, das sexualidades e dos gêneros no espaço da educação física escolar. In: RIBEIRO, Paula Regina Costa et al. (Orgs.). Educação e sexualidade: identidades, famílias, diversidade sexual, prazeres, desejos, preconceitos, homofobia. Rio Grande, RS: Editora da FURG, 2008. p. 67-75.

HALL, Stuart. A identidade cultural na pós-modernidade. 7. ed. Tradução Thomaz Tadeu da Silva e Guacira Lopes Louro. Rio de Janeiro: DP\&A, 2002. 
HEKMA, Gert. As long as they don't make an issue of it...: Gay men and lesbians in organized sports in the Netherlands. Journal of Homosexuality, v. 35, n. 1, p. 1-23, 1998.

HOOKS, Bell. Eros, erotismo e o processo pedagógico. In: LOURO, Guacira Lopes (org.). O corpo educado. Pedagogias da sexualidade. Belo Horizonte: Autêntica, 1999.

JUNQUEIRA, Rogério Diniz. Homofobia: limites e possibilidades de um conceito em meio a disputas. $B a-$ goas - Estudos gays: gêneros e sexualidades Natal, v. 1, n. 1, p. 145-165, jul./dez. 2007.

JUNQUEIRA, Rogério Diniz. Heteronormatividade e homofobia. In: JUNQUEIRA, Rogério Diniz (org.). Diversidade sexual na educação: problematizações sobre a homofobia nas escolas. Brasília: MEC; SECAD; UNESCO, 2009.

LOURO, G. L. Teoria Queer: uma perspectiva pós-identitária para a Educação. Revista de Estudos Feministas, v. 9, n. 2, p. 542-553, 2001.

LOURO, G. L. Gênero, sexualidade e educação: uma perspectiva pós-estruturalista. 2. ed. Petrópolis: Vozes, 1997.

MACKINNON, C. Toward a feminist theory of the state. Massachussets: Harvard University Press, 1991.

MARTIN, James I.; D'AUGELLI, Anthony R. How Lonely Are Gay and Lesbian Youth? Psychological Reports, 93, 2003.

MELO, R. Z. Educação Física na escola: conteúdos adequados ao 2o grau. 1995. Monografia (Graduação) Unesp, Instituto de Biociências, Departamento de Educação Física, Rio Claro, 1995.

MESSNER, Michael. Taking the field: Women, men and sports. Minnesota: University of Minnesota Press, 2002.

MOITA, G. Essências e diferenças: minorias sexuais ou sexualidades (im)possíveis. In: FONSECA, L.; SOARES, C.; VAZ, J. M. A sexologia: perspectiva multidisciplinar II. Coimbra: Quarteto, 2003.

PRADO, M. A. M.; MACHADO, F. V. Preconceito contra homossexualidades: hierarquia da invisibilidade. São Paulo: Cortez, 2008.

PRICE, Michael. Rugby as a gay men's game. Unpublished dissertation, University of Warwick, 2000.

$\mathrm{RICH}, \mathrm{A}$. Heterossexualidade compulsória e existência lésbica. Bagoas - Estudos Gays: Gêneros e Sexualidades, Natal, 4(5), jan./jun. p. 17-44, 2010. (Obra original publicada em 1980).

RODRIGUES, D. (org.). Educação e diferença. Porto: Editora Porto, 2001.

ROSEMBERG, Fúlvia. A educação física, os esportes e as mulheres: balanço da bibliografia. In: ROMERO, Elaine (org.). Corpo, mulher e sociedade. São Paulo: Papirus, 1995.

RUBIO, Katia. De protagonista a espectadoras: a conquista do espaço esportivo pelas mulheres. Movimento, Porto Alegre, 1999.

RUSSELL, Stephen T.; SEIF, Hinda; TRUONG, Nhan L. School Outcomes of Sexual Minority Youth in the United States: Evidence from a National Study. Journal of Adolescence, 2, 2001.

SCOTT, J. Gênero. Uma categoria útil de análise histórica. Educação e Realidade, São Paulo, v. 16, n. 2, 1990.

SOTELO, Maria Jose. Political Tolerance among Adolescents towards Homosexuals in Spain. Journal of Homosexuality, 39, 2000.

TORRES, M. A. A diversidade sexual na educação e o direito a cidadania LGBT na escola. 2. ed. Belo Horizonte: Autêntica Editora, 2013.

WELZER-LANG, Daniel. A construção do masculino: dominação das mulheres e homofobia. Revista Estudos Feministas, Florianópolis, v. 2, p. 460-482, 2001.

WENDEL, W.; TOMA, D.; MORPHEW, C. How much difference is too much difference? Perceptions of gay men and lesbians in intercollegiate athletics. Journal of College Student Development, 42, 2001. 